\title{
LEYES CONTRA EL MALTRATO ANIMAL EN FRANCIA Y ESPAÑA
}

\section{Loïs Laimene Lelanchon ${ }^{1}$}

\section{Introducción: El Estatuto jurídico de los animales en Francia y España}

Los sistemas legales francés y español se desarrollaron alrededor de la noción clave de "propiedad". Y por tanto, los animales siempre tuvieron un valor económico para la mayoría de la población que era esencialmente agricola. Los animales fueron usados para cosechar campos; ellos podían ser: montados, comidos, negociados o vendidos.

Principalmente, la ley trató con animales únicamente debido al valor económico que ellos representaron ${ }^{\mathrm{i}}$. La noción de propiedad definió animales en el sistema legal, todo fue articulado alrededor de la dualidad de poseído / no poseído. Si un animal tiene un propietario, es considerado "res propriae" (latín para "algo que pertenece a alguien"), si no entonces esto es una "res nullius" (latín para "algo que no pertenece a nadie"). En el caso de las "res nullius", éste puede ser sujeto de apropiación y lógicamente hacerse "res propriae". Si tomamos el ejemplo de la caza, la interacción entre los dos términos es bastante clara; los perros persiguen un ciervo salvaje mientras el cazador los sigue. En este caso, los perros son la propiedad del cazador (res propria) mientras el ciervo salvaje no pertenece a nadie (res nullius). Si el cazador coge y mata el ciervo, su cadáver será considerado su propiedad (res propriae).

Como ambos países provienen del Derecho romano, hoy día, conceden a los animales la misma personalidad jurídica.

\footnotetext{
1 Doctorando en Derecho Animal de la UAB; Máster en Derecho Animal y Sociedad (Universitat Autónoma de Barcelona, España); Máster en Derecho Internacional y Comparado del Medio Ambiente (Université de Limoges, Francia); Graduado en Derecho Internacional y Europeo (Université AixMarseille, Francia).
} 


\section{dA derecho ANIMAL la web center de los animales con derecho}

En Francia, el Código Civil y el Código Rural se refieren directamente al estatuto jurídico de los animales.

Según el Código Civil, los animales son o considerados bienes muebles o inmuebles. Sobre bienes muebles, el artículo 528 dice: "Son muebles por su naturaleza los animales y los cuerpos que pueden transportarse de un lugar a otro, o sea que ellos mismos se mueven, o sea que puedan cambiar el sitio sólo por el efecto de una fuerza extranjera. "ii

Sobre inmuebles, el artículo 524 dice: "Los animales y los objetos que el propietario de un fondo colocó allí para el servicio y la explotación de este fondo, son inmuebles por destino."iii

Sorprendentemente, el Código Rural, que realmente sólo cita animales de granja, dice en el artículo L. 214-1, "Todo animal siendo un ser sensible debe ser cuidado por su propietario en condiciones compatibles con los imperativos biológicos de su especie. "iv

España usa la misma terminología que la vigente en Francia. El Código civil Español nacional dice: en el artículo 333 "Todas las cosas que son o pueden ser objeto de apropiación se consideran como bienes muebles o inmuebles. ",

El artículo 334 incluye como "inmuebles: [...] Los viveros de animales, palomares, colmenas, estanques de peces o criaderos análogos, cuando el propietario los haya colocado o los conserve con el propósito de mantenerlos unidos a la finca, y formando parte de ella de un modo permanente. "vi

Al lado del Código civil nacional, la Comunidad Autónoma de Cataluña tiene su propio Código civil, que sólo se aplica dentro de sus fronteras. El artículo 511-1 dice, "Los animales, que no se consideran cosas, están bajo la protección especial de las leyes. Solo se les aplican las reglas de los bienes en lo que permite su naturaleza. "vii

En Francia, así como en España, la incoherencia es asombrosa entre el estatuto jurídico civil y las provisiones criminales, que proporcionan a los animales una protección especial, además de la protección relacionada con la propiedad. 


\section{Leyes antiguas contra el maltrato animal: Protección de moralidad pública}

El sistema legal francés influyó enormemente en España; por eso se pueden encontrar similitudes entre los dos países. La influencia de Francia sobre España queda patente en las primeras leyes contra el maltrato.

Para ser más correcto, es necesario hablar de leyes que se relacionan con el maltrato, más que crueldad animal. Este concepto de crueldad no fue concebido en las antiguas leyes.

\section{A. Leyes francesas contra el maltrato animal en público}

Primeramente, la ley de protección animal establecida en Francia en 1850, incriminaba el maltrato público hecho por la gente sobre animales domésticos. El General de Grammont inició el proyecto de la ley contra el maltrato hacia animales domésticos en 1849, y el proyecto final fue votado y adoptado el 2 de julio de 1850. El articulo único de la ley fue incluido en el Código penal francés. El valor legal de este texto era la protección llena de moralidad pública por proporcionar una protección parcial legal para animales domésticos.

La Ley Grammont estipulaba, "Serán castigados por una multa de cinco o quince francos, y podrán ser de uno o cinco días de prisión, para los que hayan ejercido públicamente y abusivamente maltrato hacia los animales domésticos. "viii

Antiguos documentos ${ }^{\mathrm{ix}}$ demuestran que el proyecto de ley del General de Grammont era considerablemente diferente de la versión final. Principalmente, la noción de publicidad no fue incluida. M. Defontaine introdujo el concepto de publicidad durante la tercera conferencia del texto. Sr. Defontaine, dando ejemplo de ello, mató a su caballo en una plaza pública, por no ser capaz de realizar la tarea de llevada, con lo que Defontaine consiguó mostrar su posición. El autor compartía la intención del General de Grammont, consistente en incriminar maltratos sobre animales, pero sólo respecto del argumento de protección de la moralidad pública. 
Tales hechos, fueron percibidos como ofensas hacia la moralidad pública dado que a menudo exponían una brutalidad espantosa a la población.

Para M. Defontaine, el General de Grammont, en su proyecto de ley inicial, iba demasiado lejos en nombre de la protección del animal; mientras que Defontaine, no quiso que la ley se metiera o invadiera la intimidad de la población. Además, él no quiso que esta ley limitara el derecho de propiedad, sobre todo en los componentes "usus" y "abusus". Así pues, El interés de los animales, como sujetos, no le pareció lo suficiente como para limitar este derecho.

\section{B. Leyes españolas contra el maltrato animal en público}

En España, la primera referencia a la protección de los animales en el sistema legal español es de 1877, concretamente, en las Ordenanzas Municipales de la Ciudad de Palma de Mallorca (Título VIII referente a Perros). Aunque el alcance de esta provisión, fuese estrictamente limitado a perros, y aun así, el texto era sumamente progresista. El articulo 206 señalaba “Queda prohibido maltratar a perro alguno con palos, piedras ó de otro modo cualquiera" ". El texto no se refirió a los criterios de publicidad, como fue mencionado en la ley francesa Grammont; sin embargo, su valor legal fue restringido a nivel local.

A nivel nacional, el Código Penal de 1928, del General Primo de Rivera, fue el primer texto legal para incriminar el maltrato sobre animales domésticos. El artículo 810.4 tipificaba: “los que públicamente maltrataren a los animales domésticos o los obliguen a una fatiga excesiva"xi serán penados con una multa de 50 a 500 pesetas. Comparando con la ley Grammont, esta provisión era más progresiva en su alcance. De hecho, el presente artículo incluye dos tipos diferentes de hechos humanos. El primero es el maltrato; que no se diferencia de la ley Grammont, pero el segundo fuerza a los animales a realizar tareas hasta que éstos alcanzan el punto de fatiga $y$ respecto de la condición de publicidad aún pervive en aquel sentido. En cualquier caso, es seguro decir que, el artículo 810 protegió la moralidad pública más que los animales 


\section{dA derecho ANIMAL la web center de los animales con derecho}

en si mismos. En los años ochenta y los años noventa, discusiones surgieron en España, en relación con la modificación del artículo mencionado.

Por ejemplo, en 1980, la Unión del Centro Democrático (UCD) hizo un Proyecto de Código Penal. El artículo 685 establecía: "los que maltrataren cruelmente a los animales, con ofensa de los sentimientos de los presentes, serán castigados con la pena de multa de 10 a 60 días." "xii Esta provisión fue reutilizada, en el artículo 607 de Proyecto de Código Penal de 1983 pero esta vez bajo la sección “Faltas contra el orden público"xiii.

Las provisiones en cuanto al maltrato animal, también fueron presentadas en los Proyectos de Código Penal de 1992 y 1994.

Las provisiones del Proyecto de Código Penal de 1994 fueron incluidas en la sección "Faltas contra los intereses generales". El artículo 620 establecía, “los que maltrataren cruelmente a los animales domésticos o a cualquier otros en espectáculos no autorizados legalmente, ofendiendo los sentimientos de los presentes serán castigados con la multa de diez a sesenta días" ${ }^{\text {xiv }}$. Ninguna de las provisiones anteriores fue adoptada y hubo que esperar a 1995 para que se notara la verdadera evolución. Con todo, el Proyecto de Código Penal de 1994 tuvo su importancia, tal y como anunciaba, el Código Penal español de 1995.

Aunque las leyes ya mencionadas en Francia y España principalmente fueran concentradas sobre la protección de la gente, la moralidad pública y el orden público; es crucial no minar su impacto sobre los textos legales posteriores.

\section{Leves modernas contra el maltrato animal: Protección de animales en si} $\underline{\text { mismos }}$

En Francia, el texto fundador en términos de protección animal es el Decreto $n^{\circ} 59$ 1051, que reprimie el maltrato animal; adoptado el 7 de septiembre de 1959. El decreto incriminó: "Los que hayan ejercido sin necesidad, públicamente o no, maltrato hacia un animal doméstico, o domesticado o valorado en cautividad"xv . Aquí, El retiro de la condición de publicidad, reveló la intención del legislador de proteger a 
los animales en si mismos e incriminando algunos hechos humanos. Y por tanto, a partir de 1959, la dimensión pública no fue una condición nunca más.

En España, es con el Código Penal de 1995 que los animales pudieron beneficiarse de una verdadera protección legal. El articulo 632 establecía "los que maltrataren cruelmente a los animales domésticos o a cualesquiera otros, en espectáculos no autorizados legalmente, serán castigados con la pena de multa de diez a sesenta días"xvi.

Comparado con el Proyecto de Código Penal de 1994, este texto representa una evolución importante. A partir de 1995, la condición "ofendiendo los sentimientos de los presentes" fue derogada de la redacción.

La Ley 16/70 de 4 de agosto sobre Peligrosidad y Rehabilitación social, influyó enormemente en la legislación relacionada con animales. Esta ley definía en el artículo 2.9 el estado de peligrosidad: "los que con notorio menosprecio para la comunidad o dañen a los animales, las plantas o las cosas"xvii.

Los textos ya mencionados eran las provisiones innovadoras que permitieron el desarrollo de legislaciones.

Es posible identificar las dos dimensiones claves que permitieron tal evolución: el alcance de animales protegidos por las provisiones penales y la terminología usada que permite la identificación de los hechos humanos incriminados.

\section{A. Animales protegidos por las provisiones penales}

El alcance de las provisiones penales nos permite evaluar la valoración legal, así como determinar, cuales son los animales protegidos por las leyes contra el maltrato. Seguramente, ambos países se desarrollaron en casi la misma dirección: proveyendo a los animales domésticos una protección jurídica mayor y más amplia; pero a un tiempo diferente. Además, los dos nombrados alcances no son ilimitados. 


\section{Distinción entre especie doméstica y no doméstica}

Las legislaciones francesa y española fueron en la dirección de ampliar el alcance de los animales protegidos. Poco a poco, las provisiones penales se pudieron aplicar no exclusivamente a los animales domésticos, sino que también a un tipo de especies de animales silvestres.

\section{a. Una delimitación bastante clara en Francia}

Mientras la ley Grammont sólo podía aplicarse a los animales domésticos, el Decreto ${ }^{\circ}$ 59-1051, que reprime los maltratos hacia los animales, aumentó enormemente el alcance de animales protegidos por sus provisiones.

Es justo decir que la ley Grammont sólo fue limitada a los animales domésticos, principalmente porque en aquel tiempo la delimitación entre animales domésticos y salvajes no era bastante relevante. Sin embargo, después de la adopción de la ley, la distinción entre especie doméstica y no doméstica fue introducida en la discusión pública.

La Cour de Cassation, el tribunal judicial, el más alto de Francia, definió el 14 de marzo de 1861, que es un animal doméstico. En su decisión el tribunal cita que, el término "animales domésticos" se refiere a los "seres animados que viven, son criados y alimentados, bajo el techo y el cuidado de los humanos" "xviii.

La definición fue demasiado restrictiva ${ }^{\text {xix }}$ por lo tanto; el Tribunal amplió su definición el 16 de febrero de 1895 en una nueva decisión. Un animal doméstico "vive bajo la vigilancia humana, y no sólo bajo su techo" ${ }^{\text {xx }}$. Según la jurisprudencia de aquel tiempo, el factor clave que determinaba si un animal era doméstico o salvaje; era la interacción que éste tenía con los humanos.

Seguramente, la diferenciación contemporánea de animales salvajes y domésticos es clara.

En el Derecho francés, la Instrucción NP/94/6 ${ }^{\mathrm{xxi}}$, documento no vinculante, estableció 


\section{dA derecho ANIMAL la web center de los animales con derecho}

en 1994, las definiciones de los términos "especie doméstica" y "especie no doméstica".

Según este documento:

"Son considerados como perteneciendo a las especies no domésticas, los animales que no han sido modificados por ningún proceso de selección por parte de los humanos. Al contrario, las especies domésticas han estado bajo una presión selectiva, continua y constante. Esta presión selectiva condujo a la formación de un grupo de animales que adquirieron características estables genéticamente transmisibles. Es decir, que un animal de una especie no doméstica haya nacido en su hábitat natural o en cautividad, y que el período de tiempo sostenido en cautividad no tenga ninguna influencia sobre su naturaleza non-doméstica es, al máximo, lo que podemos denominar como un animal de una especie salvaje que está 'domesticado' o 'mantenido en cautividad' ".

La Circulaire relacionada a la lista de especies, razas y variedades de animales domésticos ${ }^{\mathrm{xxii}}$ reafirmó la definición anterior.

En 2006, el Arrêté ministériel ${ }^{x x i i i}$, que es un documento vinculante, modificó la definición adoptada en 1994 y estableció, en cambio, una definición técnica.

"Son considerados como animales domésticos: los animales que pertenecen a poblaciones animales seleccionadas, o si tienen los dos padres perteneciendo a poblaciones animales

seleccionadas.

Una población animal seleccionada es, una población de animales que se diferencia de las poblaciones genéticamente más cercanas, debido a un juego de características reconocibles y hereditarias, que son la consecuencia de una política de gestión específica y razonada de los acoplamientos. Y una especie doméstica es, una especie de la cual todos los representantes pertenecen a poblaciones animales seleccionadas, o que tienen los dos padres pertenecientes a poblaciones animales seleccionadas".

La Organización Mundial de Sanidad Animal (OIE) definió también el término 'animal silvestre'. La definición se concentra sobre el proceso de selección artificial en animales;

Según la OIE, el término 'animal silvestre' designa un animal cuyo fenotipo no se ha 
visto afectado por la selección humana y que vive independiente de la supervisión o el control directo de seres humanos ${ }^{\mathrm{xxiv}}$. $\mathrm{Y}$ al contrario, el término 'animal doméstico' designo un animal cuyo fenotipo se ha visto afectado por la selección humana y que vive dependiente de la supervisión o el control directo de seres humanos.

La distinción ahora está bien establecida en Francia e impide la tenencia de algunas especies de animales silvestres.

\section{b. Una delimitación confusa en España}

Si la determinación entre animales domésticos y salvajes es un concepto claro en Francia, no no ocurre los mismo en España. En efecto, no hay ninguna lista nacional que establezca que especie se puede considerar doméstica.

El articulo 465 del Código civil español ${ }^{\mathrm{xx}}$ hace la distinción entre cuatro términos:

- Los animales domésticos

- Los animales mansos

- Los animales domesticados

- Los animales amansados

La distinción no es fácil, sin embargo, las dos últimas categorías parecen referirse a los animales que están en un proceso de domesticación. En este articulo, los animales domesticados son asimilados a los domésticos, y los amansados a los mansos; si conservan la costumbre de volver a casa del poseedor. Todos los otros animales son considerados como componentes de la fauna (res nullius).

A dichas provisiones nacionales, se pueden añadir provisiones regionales. En efecto, diecisiete (diecinueve con las dos ciudades) Comunidades Autónomas componen el estado español. En teoría, cada Comunidad tiene su propia legislación relacionada a la protección de los animales. El alcance de las provisiones regionales sobre la materia, por lo general, tiene su propia definición en cuanto a lo que es un "animal doméstico". 


\section{El alcance de las provisiones penales}

a. Extensión de la protección jurídica los animales amansados o silvestres mantenidos en cautividad: la cautividad como base de protección jurídica

Con la evolución de la sociedad francesa, era necesario en 1959, no limitar la legislación contra el maltrato solamente a los animales domésticos. Por lo tanto, las provisiones incluidas en el Código penal francés, después de la adopción del Decreto ya mencionado, se aplicaron a los animales domésticos, amansados y cautivos. Sin embargo, no hay ninguna referencia explícita a los animales salvajes. En concreto, lo que interesaba al legislador era la dependencia de los animales de la supervisión humana o el factor de control humano, más que el tipo de animales. La referencia a los "animales domésticos" fue incluida porque, esto era al principio, un concepto claro establecido, y porque esto, automáticamente, supuso tal dependencia.

Naturalmente el término "animales domésticos" se quitó del título. De todos modos el titulo del Decreto puede ser criticado, es decir, La utilización del término 'los animales' engañaba porque esto asumía que el Decreto cubría todos los animales, cuando realmente, los animales silvestres no cautivos son excluidos.

En Francia, desde 1959, el alcance de las numerosas leyes de maltrato es inalterable; la parte de la legislación: "animales domésticos o amansados o animales mantenidos en cautividad" $^{\text {xxvi }}$ no fue modificada por ninguna ley. Parece pues, que las provisiones penales sólo se pueden aplicar a los diferentes tipos de animales ya mencionados.

\section{b. Alcance de animales protegidos por la ley en España}

En España, el alcance de la protección para los animales en las leyes contra el maltrato, no se extendió tan radicalmente como fue el caso en Francia.

En 1928, las provisiones del Código penal sólo se refirieron a los animales domésticos. La reforma de 1995 añadió a las provisiones preexistentes (que cubrieron exclusivamente los animales domésticos) la sentencia "cualquier otro espectáculo 
ilegal"xxvii. Este término significa que el artículo $632 \mathrm{CP}$ se aplicó a los animales domésticos y a todos los demás usados en espectáculos ilegales, como por ejemplo, peleas de animales. Es decir, que el criterio usado ha sido: la utilización de animales en espectáculos no autorizados por la administración. En 2003, el alcance anterior permaneció inalterado. Las provisiones que se relacionaron con el abandono (artículo 631.2 CP) o el maltrato grave (337 CP) sólo se podían aplicar a los animales domésticos.

El año 2010 se realizó un cambio importante, los animales amansados fueron incluidos en el alcance de las provisiones relacionadas exclusivamente con el maltrato grave. En cuanto al maltrato menor y el abandono, no hubo ninguna extensión. Sólo los animales domésticos y amansados o cualquier otros, usados en espectáculos no autorizados, fueron protegidos por las leyes sobre el maltrato animal.

El Anteproyecto de Ley Orgánica de $2012^{\text {xxviii }}$, por la que se modifica la Ley Orgánica 10/1995 del Código Penal, tendría como mérito corregir parcialmente, la incoherencia latente en relación con el alcance de las diferentes provisiones. En efecto, mientras los nuevos artículos 337 y 337 bis del Código sólo recordarían y compilarían las provisiones existentes, en cuanto al abandono, el alcance sería ampliado, incluyendo los animales amansados.

Comparando con las provisiones francesas, el alcance de las provisiones españolas parece bastante limitado. Porque, los animales silvestres en cautividad son totalmente excluidos de la protección legal si no son amansados.

A menudo, la confusión se manifiesta en el ámbito de la distinción entre animales domésticos y animales de compañía. Con el fin de añadir claridad en todas estas previsiones legales, Francia y España, deberían adoptar una lista positiva de animales de compañía con todos los requisitos para una tenencia responsable. Y dentro de estas listas, debería haber exclusivamente los animales de compañía que se pueden tener sin alterar su bienestar. Una y otra lista, deberían establecer un inventario de todas las especies domésticas, enfocándose sobre el aspecto genético, de conformidad con las definiciones de la OIE. 
Finalmente, todos los animales que no son mencionados en aquellas listas deberían ser considerados como silvestres.

Seguramente, una reforma bien pensada sobre la distinción entre los animales de compañía, domésticos, amansados, silvestres en cautividad o en su hábitat natural, se debería reflejar en las previsiones penales.

B. Evolución de los hechos humanos incriminados: análisis detallado de la terminología

\section{Hechos incriminados en Francia}

En Francia, la noción de "maltrato" ha sido usada profusamente a lo largo del desarrollo de legislación relacionada con la protección animal. En 1850, la ley Grammont incriminó el acto "de maltratar abusivamente" un animal doméstico. El término "abusivamente" se refería a la voluntad de incriminar maltratos excesivos, como fue explicado en la nota de pie de página de la ley Grammont. El término "maltrato" quería decir en aquel tiempo, un tratamiento brutal.

Mientras el Decreto n59-1051 reprimiendo el maltrato hacia los animales usó la misma noción de maltrato, el concepto de necesidad fue introducido y presentado como una causa de exoneración. La necesidad es un concepto de aspecto borroso; está definido por el artículo 122-7 del Código penal francés ${ }^{x x i x}$. Se refiere a la situación que permite a alguien cometer un acto ilegal para conservar un bien jurídico mayor, sin tener cualquier otra opción. Si el demandado pudiera demostrar que él o ella actuaron bajo la necesidad, el maltrato no era reprensible.

La ley 63-1143 del 19 de noviembre de 1963 sobre la protección de los animales ${ }^{\mathrm{xxx}}$ guardó el concepto de necesidad, pero substituyó el acto de maltrato por el 'de crueldad'. Esto implicaba reconocer un nivel más severo de maltrato. Con este término, el alcance de los hechos incriminados fue enormemente restringido, excluyendo el maltrato común (sin crueldad subsecuente).

El concepto de crueldad, generalmente, es definido como la voluntad de causar un dolor o sufrimiento, y en algunas circunstancias el beneficio de un cierto placer relacionado con el logro del hecho cruel. 
Los tribunales han definido, el concepto de crueldad en el campo de la protección animal.

"El hecho de crueldad se diferencia de la simple brutalidad, porque está inspirada en la maldad pensada y traduce la intención de infligir el sufrimiento" ${ }^{n \times x i}$. Otros tribunales, definieron el concepto como "cerca del barbarismo y el sadismo"xxxii, "denotó una voluntad o un instinto pervertido" ${ }^{\text {xxxiii }}$.

Podemos utilizar algunos ejemplos concretos para demonstrar lo que representa un hecho de crueldad: realizar una cirugía de castración sin anestesia sobre un caballo ${ }^{\text {xxiv }}$; disparar a un perro abandonándolo y dejándolo con la garganta abierta sin cuidado veterinario durante 48 horas $^{\mathrm{xxx}}$.

Es cierto que, esos ejemplos anteriores, son casos obvios de crueldad sobre animales, pero otros ejemplos no son tan obvios. Golpear a un lobo blanco domesticado o cautivo, sin necesidad, ha sido considerado como un hecho de crueldad $^{\text {xxxvi }}$, mientras eso representa con mayor probabilidad un caso de maltrato común.

En 1976, el artículo 13 de la ley 76-629 sobre la Protección de la Naturaleza ${ }^{\text {xxvii }}$, es un artículo que modificó el artículo 453 del Código penal francés. La ley introdujo el término "maltratos graves" a las provisiones preexistentes. Ambos actos, crueldad y maltratos graves eran entonces reprensibles. La parte en relación con la necesidad había sido guardada.

En 1992, la ley 92-1336 del 16 de diciembre ${ }^{\text {xxxviii }}$ cambio la redacción del artículo en relación con la protección de los animales. Mientras el contenido permaneció intacto, la ley parecía incriminar más los hechos en si mismos que no las personas. El artículo 453 se convirtió en el artículo 511-1 y fue incluido en un Capítulo titulado "Maltratos graves y hechos de crueldad sobre animales ".

En 1994, una reforma ambiciosa del Código penal fue operada. El artículo 511-1 se convirtió en el artículo 521-1.

El artículo 22 de la ley 99-5 sobre animales peligrosos y callejeros y la protección animal $^{\text {xxxix }}$ modificaron el artículo 521-1 del Código penal quitando de su redacción el concepto de "necesidad". 
La ley 2004-204 sobre la adaptación de la justicia a las evoluciones de la criminalidad ${ }^{\mathrm{xl}}$, introdujo, además del maltrato grave y hechos de crueldad, el término "maltrato sexual". Las tres conductas se pueden reprehender.

Hoy en día, el artículo 521-1 del Código penal francés se redacta así:

"La imposición, en público o de otra manera, de maltrato grave, incluyendo el maltrato sexual, o la comisión de un acto de crueldad sobre cualquier animal doméstico o amansado, o cualquier animal mantenido en cautividad, se castiga con un encarcelamiento de dos años y una multa de 30000 euros" $^{\text {xli }}$.

\section{Hechos incriminados en España}

En España la terminología utilizada en las provisiones relacionadas con los animales no ha sido sujeto de evolución constante, como si ha sucedido en Francia.

Sin embargo, es posible identificar tres cambios principales en la redacción de las previsiones penales.

En 1928, dos tipos de conductas eran reprensibles: el 'maltrato' y 'conducir a una fatiga excesiva'.

Con la reforma del Código penal español en 1995, en relación a los animales se prohibió conducir a un animal a fatiga excesiva. Mientras que, el artículo 632 se centró en una infracción de nivel único: el "maltrato con crueldad", la introducción del término 'con crueldad', como criterio, limitó enormemente el alcance de la provisión ya restringida.

Con la Ley Orgánica 15/2003 ${ }^{\text {xlii }}$, el legislador distinguió dos niveles de maltrato: el leve y el grave.

En 2003, el maltrato leve fue clasificado como falta en el sistema penal español. El contenido del artículo 632 permaneció inalterado ("los que maltrataren cruelmente"), y fue atribuido a esos casos de maltrato especifico. Y pocos cambios en la redacción ocurrieron en cuento a las penas.

El maltrato grave, es decir "los que maltrataren con ensañamiento e injustificadamente" fue calificado como delito en el artículo 337. Según el artículo 139.3 del Código Penal 
español, el término "ensañamiento" se refiere a: "aumentando deliberada $e$ inhumanamente del dolor del ofendido" ${ }^{\text {"xliii }}$.

El artículo 337 determinó también condiciones en cuanto al prejuicio y al impacto del acto sobre la salud del animal. Para que se considerase un delito de maltrato grave debía sucederse la muerte o lesiones, producidas por un grave menoscabo físico.

Conjuntamente a la dualidad de la noción de maltrato, fue introducido, en el artículo 631.2 la falta de abandono de animales domésticos. El abandono era reprensible si se podía demostrar que el acto ya mencionado puso el animal en condiciones de peligro para su vida o integridad. Sin duda, la intención del legislador era de luchar contra el "desecho ilícito" de animales en el hábitat natural; y probablemente orientar a la gente para que abandone su animal de compañía en refugios.

Sin embargo, la redacción de artículo 631.2 es criticable. Porque en efecto, el abandono siempre supone un para la vida o integridad del animal, así que no es defendible el rechazo a la entrega en refugios de animales.

En 2010, la Ley Orgánica 5/2010 xliv no reformó profundamente la legislación; esta estableció, simplemente, una protección legal más elevada. Por ejemplo, las penas relacionadas con el abandono habían sido aumentadas, la multa pasaba de 10 a 30 días, mientras que antes era de 15 días a dos meses.

Las provisiones sobre el maltrato animal leve permanecieron inalterables. Sin embargo, se realiza un cambio sustancial en la redacción de los artículo 337 sobre el maltrato grave. El legislador decidió quitar el término 'ensañamiento' porque hizo difícil la aplicación y interpretación del antiguo artículo 337.

El artículo 337 reformado quedó rectado de tal modo: "El que por cualquier medio o procedimiento maltrate injustísimamente a un animal doméstico o amansado causándole la muerte o lesiones que menoscaben gravemente su salud, será castigado con la pena de tres meses a un año de prisión". La ley también incluyó como sanción la inhabilitación especial de uno a tres años, para el ejercicio de profesión, oficio o comercio que tenga relación con los animales. 
Considerando las imperfecciones contenidas en las provisiones ya mencionadas y que se aplican hoy día, una gran reforma del Código Penal está pendiente desde 2012. El Anteproyecto de Ley Orgánica del 23 de noviembre de $2012^{\text {xlv }}$ propuso una estructura distinta de la que hay hoy en vigor. Es decir, la clasificación que funciona sobre tres niveles: crimen, delito y falta ha cambiado, y las faltas probablemente desaparecerían. La última reforma supone, un Anteproyecto de Ley Orgánica que tendría como finalidad endurecer las provisiones contra la ofensas a los animales. Las provisiones del artículo 632 sobre el maltrato leve deberían ser incluidas en el artículo 337, mientras el artículo 337 bis incluiría las provisiones que se relacionan con el abandono.

La consecuencia sería la accesión y la inclusión de esas provisiones a la categoría de delito y por tanto, la redacción del nuevo artículo 337 es considerablemente diferente.

Actualmente, el párrafo 1 todavía se refiere a "El que por cualquier medio o procedimiento maltrate injustificadamente", sin embargo la parte en relación con el resultado del hecho ha sido limitada: "causándole lesiones que menoscaben gravemente su salud". Al respecto también se está estudiando aumentar las penas.

El párrafo 2 establece las circunstancias agravantes:

- la utilización de armas, instrumentos... y formas concretamente peligrosas para la vida del animal,

- Presencia de 'ensañamiento'

- Si el acto tiene como consecuencia para el animal la pérdida o inutilidad de un órgano, miembro o un sentido

El párrafo 3 se relaciona con la muerte del animal después del maltrato. En ese caso, algunas penas especiales se aplicarían de: seis a dieciocho meses de prisión e inhabilitación especial de dos a cuatro años para el ejercicio de profesión, oficio o comercio que tenga relación con los animales y para la tenencia de animales domésticos o amansados.

El párrafo 4 se refiere al maltrato cruel leve y la pena correspondiente es una multa de uno a seis meses. 
Conjuntamente con legislaciones sobre la protección de los animales, bastante desarrolladas, Francia y España tienen en común tradiciones, conocidas a través el mundo que perjudican la vida de los animales.

\section{$\underline{\text { IV. Los actos crueles pero legales, como limitaciones a las leves contra el maltrato }}$}

A pesar de las provisiones contra el maltrato, que se pueden encontrar en los códigos penales francés y español, algunas actividades permanecen legales.

Los dos ejemplos asombrosos que representan excepciones a las provisiones anteriores son tradiciones culturales como: las corridas de toros y las peleas de gallos. Pueden encontrarse corridas de toros en España y también en el sur de Francia mientras las peleas de gallos se pueden encontrar en pocas partes de España y en el norte de Francia.

\section{Tauromaquia, un espectáculo cruel pero legal entre humanos y animales}

La terminología usada en ambos países para designar la actividad ya mencionada es interesante.

En efecto, en el artículo 521-1 del Código Penal francés, la actividad de tauromaquia está mencionada como "course de taureaux ".

En la cultura tradicional española, el término usado para identificar esta práctica es "corrida de toros". Ambos términos tienen la misma significación y pueden ser literalmente traducidas por " corrida de toros ".

Sin embargo, en la lengua inglesa, se utiliza el la palabra "bullfighting" para mencionar esta actividad.

"Corrida de toros" y "Pelea de toros" (humano-animal) son dos términos considerablemente diferentes en sus significaciones. El término "corrida" implica apenas cualquier maltrato sobre animales, mientras el empleo de "pelea" es bastante explícito.

El Consejo Constitucional francés definió con precisión lo que el término "course de taureaux" significa. Esto se refiere a "las corridas de toros con o sin matanza, así como, literalmente corridas de toros" ${ }^{\mathrm{xlvi}}$. 


\section{a. Francia}

Como simple recordatorio, en el sistema jurídico francés, la primera ley contra el maltrato se creó en 1850. Y La tauromaquia fue introducida en Francia en 1853 cerca de Bayona para honrar a la Condesa Eugenia Montijo, esposa de Napoléon III.

La tauromaquia se desarrolló en el sur de Francia en los años 80. Por eso, en 1884 la pregunta fue, si la ley Grammont que realmente trata de maltratos públicos sobre animales domésticos se podía aplicar. El Ministro del Interior acudió a la Corte de Casación, el tribunal judicial más alto de Francia, porque la cuestión a determinar era: ¿pertenecen los toros de lidia a una raza que puede ser considerada doméstica?

El 16 de febrero de 1895, la Corte de casación declaró que los toros de lidia se podían considerar domésticos ${ }^{\text {xlvii }}$. Por lo tanto, la ley Grammont se podía aplicar, para prohibir e incriminar los espectáculos de tauromaquia. Entre 1895 y 1951, las provisiones del la ley Grammont y la decisión de la Corte de casación no fueron respetadas. Dado que las comunidades regionales no reconocieron la legitimidad de la República centralizada y los tribunales regionales no estuvieron inclinados a aplicar las provisiones penales.

La tauromaquia se volvió una práctica legal en Francia en 1951. Un párrafo relativo a la tauromaquia o "courses de taureaux", como menciona la ley, estuvo introducido en el artículo único de la ley Grammont. La ley n51-461 de 24 de abril de 1951 complementando la ley del 2 de julio de 1850 sobre el maltrato hacia animales domésticos convirtió la tauromaquia en una actividad legal.

Como redactado en el párrafo ya mencionado, "las provisiones del artículo presente no son aplicables a las corridas de toros donde se puede demonstrar una tradición ininterrumpida",xlviii.

La introducción de un párrafo como tal implica que la ley n51-461 reconozca que la tauromaquia representa una forma de maltrato y que los toros de lidia son una raza doméstica.

En 1959, el Decreto n59-1051, reprimiendo el maltrato hacia los animales añadió el adjetivo "local". El concepto de "tradición local ininterrumpida" representa una noción 
vaga, no delimitada en el tiempo o en el espacio. Considerando que la ley no identifica regiones o ciudades donde la tauromaquia representa una tradición, la carga se imputó a los jueces.

En relación a este término, la Corte de Casación y los jueces de primera y segunda instancia se diferencian enormemente en sus interpretaciones respectivas. Los jueces locales tienden a interpretar el término generosamente y extensivamente.

Por ejemplo, el Tribunal de apelación de Toulouse designó los Pirineos, la Garona, la Provenza, el Languedoc, la Cataluña francesa, Gascuña, Landas y el País Vasco como localidades con una tradición fuerte e importante de tauromaquia. Según el mismo Tribunal, organizar tales espectáculos en instalaciones permanentes o no permanentes a intervalos regulares, es la indicación de una tradición fuerte. El Tribunal sigue "la preservación de la tradición tiene que ser evaluada dentro del marco de un grupo demográfico" ${ }^{\text {"xlix }}$.

La Corte de Casación, el Tribunal judicial lo más alto, tiene una interpretación más restrictiva del término "tradición local ininterrumpida". El adjetivo "local" tiene que ser interpretado de un modo estricto. En efecto, tiene que ser probado que la tradición existió en esta misma localidad (in situ). El hecho de que el lugar de situación sea cerca de una ciudad donde la tauromaquia es una tradición, no es relevante o suficiente.

Para cumplir con el término "ininterrumpido", el Tribunal declaró que los espectáculos taurinos tenían que estar organizados regularmente ${ }^{1}$. El hecho de que, tales espectáculos no hayan sido fundados por motivos involuntarios, como la indisponibilidad de las arenas o la prohibición administrativa puede ser invocado ante un tribunal.

En septiembre 2012, el Consejo Constitucional declaró el párrafo que se relaciona con la derogación otorgada a la tauromaquia de conformidad con la Constitución francesa. Dos organizaciones antitaurinas abogaron que había una rotura de igualdad ante la ley. Así pues vemos que, por un lado la actividad litigiosa es legal en algunas partes de Francia y de otra parte, hay territorio francés que caería bajo las provisiones penales.

En su decisión, el Consejo no señalaba ninguna rotura de igualdad. Según la decisión, el principio de igualdad no impide tratar de manera diferente las personas que están en situaciones diferentes ${ }^{\text {li }}$. En definitiva, el Consejo aplicó el modelo de conexión racional de la igualdad . 


\section{b. España}

Es bastante confuso cuando situar el nacimiento de la tauromaquia. Algunas fuentes hablan de aproximadamente 815 años.

Lo que está claro es que, la legislación relativa a la protección de los animales es posterior a la tradición taurina. Las provisiones penales españolas han sido construidas alrededor de esta actividad, y siempre incluyen una frase que permite realizar la actividad de tauromaquia.

La única excepción que puede ser indicada es la del Código civil de 1928, que precisamente, no se refirió a la actividad taurina. Ya que, la excepción del artículo 810.4 se aplicó exclusivamente a los animales domésticos ${ }^{\text {lii. }}$ Y es muy probable que los toros de lidia no estuvieran considerados raza doméstica en aquel tiempo, como hoy día.

Según el artículo 632 del Código Penal español de 1995, las corridas de toros son espectáculos autorizados y entonces legales. El alcance de este artículo se limita a los espectáculos no autorizados por la administración. Por lo tanto, la tauromaquia no puede ser incriminada.

Desde 2003 y la creación del delito de maltrato grave, permanece en una incoherencia fuerte. Las provisiones que se relacionan con el maltrato grave no incluyen ninguna excepción para los espectáculos autorizados.

Es probable que el término "injustificadamente" sea la palabra clave que impide a la tauromaquia entrar en el alcance de las provisiones sobre el maltrato grave. En efecto, unos podrían argumentar que la tauromaquia se justifica por el hecho de que representa una actividad económica, una mañera de mantener viva una tradición, o una manifestación de la expresión de libertad artística.

Las corridas de toros no son autorizadas en el entero territorio español. Sobre diecinueve Comunidades Autónomas que componen el Estado español, dos no permiten esos espectáculos: las Islas Canarias y Cataluña.

Por causa de una frecuentación baja de público, la última corrida de toros se celebró en las Islas Canarias en 1984. En 1991, esta Comunidad Autónoma adoptó una ley de 
protección de los animales que no incluyó en su artículo 5 derogación expresa para la actividad taurina, mientras que había una para las peleas de gallos. Invocando el artículo 1 que estableció el alcance, unos argumentaron que la prohibición de "peleas, espectáculos y las 'fiestas' que contenian maltrato, la crueldad o sufrimiento", liii no se debía aplicar a los toros de lidia, dado que ellos no se podían considerar animales domésticos. Por el contrario, el artículo 2 afirma que los animales domésticos son estos que, para su supervivencia, dependen de los humanos, en relación a la alimentación. Y definitivamente, después de 1991 no se organizaron mas corridas de toros en Canarias.

En 2010, una Iniciativa Legislativa Popular propuso una ley con finalidad de prohibir las corridas de toros en la Comunidad Autónoma de Cataluña. Como consecuencia, el Parlamento catalán adoptó el proyecto de la ley el mismo año. Aunque, esta iniciativa es más política que basada en la ética. En efecto, los toros de lidia representan el símbolo de España por lo tanto el texto fue percibido como una forma de protesta por parte de Cataluña contra el Estado español. De todas formas, la prohibición entró en vigor en enero 2012. Las provisiones que prohíben las corridas de toros fueron incluidas ${ }^{\text {liv }}$ en el artículo 6 del Decreto Legislativo 2/2008, de 15 de abril, por el que se aprueba el Texto refundido de la Ley de protección de los animales ${ }^{\text {lv }}$. Con que, las corridas de toros ya no son autorizadas en Cataluña. Se ha acudido al Tribunal Constitucional para debatir la conformidad de esta ley que prohíbe los corridas de toros, alegando la permisión de la Constitución española, y la decisión está todavía pendiente de resolver por el tribunal.

\section{Peleas de gallos, un espectáculo cruel y entre animales}

Las peleas de gallos representan también una práctica permitida en algunas partes de ambos países.

En España, las peleas de gallos están autorizadas en tres Comunidades Autónomas: las Islas Canarias, Andalucía y Murcia.

Aunque se prohibieron las corridas de toros en las Islas Canarias, las peleas de gallos permanecen legales en localidades donde son una tradición. Según el artículo 5 de la Ley 8/1991, de 30 de abril, de protección de los animales ${ }^{\mathrm{lvi}}$, las peleas de gallos tienen 
que estar organizadas en instalaciones cerradas y los menores de menor que 16 años no pueden asistir. Más, la construcción de nuevas arenas de peleas de gallos queda prohibida.

La Comunidad Autónoma de Murcia prohíbe la utilización de animales de compañía para pelear. Sin embargo, según el artículo 1 de la Ley 10/1990, de 27 de agosto, de protección y defensa de los animales de compañía ${ }^{\text {lvii }}$, los gallos no se pueden considerar animales de compañía, por eso permanecen permitidas las peleas de gallos.

En Andalucía, una prohibición general relativa a las peleas de gallos si ha sido establecida. Aún así, la derogación contenida en el artículo 4 de la Ley 11/2003, de 24 de noviembre, de protección de los animales ${ }^{\text {lviii }}$, es sumamente permisiva, es decir, sólo se permiten las peleas de gallos que usan gallos genéticamente seleccionados para aquel objetivo.

En Francia, un párrafo relacionándo con peleas de gallos ha sido añadido desde 1964. La ley 64-690 introdujo después del párrafo relativo a las corridas de toros, la frase siguiente "Tampoco ellas [provisiones contra el maltrato] se aplican a las peleas de gallos en localidades donde una tradición ininterrumpida puede ser establecida"lix.

Puede ser indicado que el término "establecido" es diferente del término "demostrado" usado para corridas de toros. "Establecido" se refiere a un hecho, mientras "demostrado" se refiere al interés del público.

\section{$\underline{\text { V. Conclusión }}$}

En cuanto a la protección jurídica de los animales, Francia ha abonado el terreno para que España pueda adoptar una legislación sólida.

Las legislaciones de Francia y España están basadas en la tradición de derecho romano y encuentran dificultades separándose del concepto de animal-objeto.

Al principio, la protección penal se inició en ambos países sobre la fundación de la protección de moralidad pública.

Más tarde, las provisiones penales que se relacionan con la crueldad intencional hacia los animales se formaron alrededor de la noción de maltrato. La sociedad consiguió 
reconocer el derecho para los animales de no ser maltratados; como sacó a la luz el famoso representante de la Ilustración, Jean-Jacques Rousseau en $1755^{1 \mathrm{x}}$.

Sobre la marcha, Francia y España aumentaron el alcance de animales protegidos, yendo de animales exclusivamente domésticos a algunos tipos de animales silvestres. El alcance de los hechos humanos incriminados también ha sido ampliado, introduciendo con reforma nuevos conceptos. Paralelamente, la jurisprudencia siguió trayendo nuevos desafíos en cuanto a la interpretación de provisiones a menudo generales y vagas. Y aquellos desafíos han forzado al legislador a introducir términos más exactos.

Al mismo tiempo, prácticas crueles obvias, relacionadas con la tradición, se han beneficiado de derogaciones a las provisiones penales, debilitando el valor legal y la coherencia de las leyes contra el maltrato animal.

' Cour de Cassation, 1ère chambre civile, Lunus, 16 Janvier 1962

ii Code Civil Français, article 528

iii Code Civil Français, article 524

${ }^{\text {iv }}$ Code Rural Français, article L. 214-1

` Código Civil Español, artículo 333

${ }^{v i}$ Código Civil Español, artículo 334

vii Codi Civil de Catalunya, article 511-1

viii Loi du 2 juillet 1850 relative aux mauvais traitements exercés envers les animaux domestiques, dite "Loi Grammont', p. 5

ix Proposition de M. le Général de Grammont, p. 5

x Ordenanzas Municipales de la Ciudad de Palma de Mallorca de 1877, artículo 206:

"Queda prohibido maltratar a perro alguno con palos, piedras ó de otro modo cualquiera".

${ }^{x i}$ Código Penal de 1928 del General Primo de Rivera, artículo 810.4 :

"Los que públicamente maltrataren a los animales domésticos o los obliguen a una fatiga excesiva"

xii Código Penal de la UCD de 1980, artículo 685:

"Los que maltrataren cruelmente a los animales, con ofensa de los sentimientos de los presentes, serán castigados con la pena de multa de 10 a 60 días" 
xiii Propuesta de Anteproyecto de Código Penal de 1983, artículo 607:

"Faltas contra el orden público"

xiv Anteproyecto de Código Penal de 1994, artículo 620 :

"Los que maltrataren cruelmente a los animales domésticos o a cualquiera otros en espectáculos no autorizados legalmente, ofendiendo los sentimientos de los presentes y que serían casti-gados con la multa de diez a sesenta días"

xv Décret $n^{\circ}$ 59-1051 du 7 septembre 1959 réprimant les mauvais traitements exercés envers les $\underline{\text { animaux, p. } 6}$

xvi Código Penal Español de 1995, artículo 632:

"Los que maltrataren cruelmente a los animales domésticos o a cualesquiera otros en espectáculos no autorizados legamente, serán castigados con la pena de multa de diez a sesenta días."

xvii Ley 16/1970, de 4 de agosto, sobre peligrosidad y rehabilitación social

xviii Cour de Cassation, chambre criminelle, 14 mars 1861 : D.P. 1861, 1, p. 184

${ }^{x i x}$ Revue semestrielle de droit animalier, 2/2010, p.16-17

${ }^{x x}$ Cour de Cassation, chambre criminelle, 16 février 1895, S. 1895, I, p.269

xxi Instruction NP/94/6 du 28 octobre 1994

xxii Circulaire du 12 octobre 2004 relative à la Liste des espèces, races et variétés d'animaux domestiques xxiii Arrêté du 11 août 2006 fixant la liste des espèces, races ou variétés d'animaux domestiques

${ }^{x x i v}$ World Organisation for Animal Health (OIE), Terrestrial Animal Health Code, Glossary

${ }^{x x v}$ Código Civil Español, artículo 465

xxvi Décret $n^{\circ}$ 59-1051 du 7 septembre 1959 réprimant les mauvais traitements exercés envers les animaux, p. 6

xxvii Código Penal Español de 1995, artículo 632:

"Los que maltrataren cruelmente a los animales domésticos o a cualesquiera otros en espectáculos no autorizados legamente, serán castigados con la pena de multa de diez a sesenta días."

xxviii Anteproyecto de Ley Orgánica por la que se modifica la Ley Orgánica 10/1995, de 23 de noviembre, del Código Penal, artículos 337 y 337 bis

xxix Code Pénal français, article 122-7

xxx Loi $n^{\circ} 63-1143$ du 19 novembre 1963 relative à la protection des animaux

xxxi Paris 2 février, 1977 JCP 1978 II 18843, note R. de L ; Gaz. Pal 1977

xxxii Paris, 9 octobre 1971 : Gaz. Pal. 1972. 1. 410.

xxxiii Tribunal Correctionnel de Nîmes, 29 Juin 1973 : Gaz. Pal. 1979. 1. 175. 
xxxiv Pau, 24 avril 2001 : JCP 2001. IV. 3102

xxxv Paris, 16 octobre 1998 : Dr. Pénal 1999. 51 (1 ${ }^{\text {er }}$ arrêt), obs. Véron.

xxxvi Tribunal Correctionnel de Bobigny, 28 septembre 1998 : Gaz. Pal. 1999. 2, chron. crim. 155.

xxxvii Loi $n^{\circ} 76-629$ du 10 juillet 1976 relative à la protection de la nature

xxxviii Loi n 92-1336 du 16 décembre 1992 relative à l'entrée en vigueur du nouveau code pénal et à la modification de certaines dispositions de droit pénal et de procédure pénale rendue nécessaire par cette entrée en vigueur

xxxix Loi $\mathrm{n}^{\circ}$ 99-5 du 6 janvier 1999 relative aux animaux dangereux et errants et à la protection des $\underline{\text { animaux }}$

${ }^{x l}$ Loi $n^{\circ}$ 2004-204 du 9 mars 2004 portant adaptation de la justice aux évolutions de la criminalité

xli Code Pénal Français, article 521-1

xlii Ley Orgánica 15/2003, de 25 de noviembre, por la que se modifica la Ley Orgánica 10/1995, de 23 de noviembre, del Código Penal

xliii Código Penal Español, artículo 139

xliv Ley Orgánica 5/2010, de 22 de junio, por la que se modifica la Ley Orgánica 10/1995, de 23 de noviembre, del Código Penal

xlv Anteproyecto de Ley Orgánica por la que se modifica la Ley Orgánica 10/1995, de 23 de noviembre, del Código Penal, artículos 337 y 337 bis

xlvi Commentaire de la Décision n²012-271 QPC du 21 septembre 2012

xlvii Cour de Cassation, chambre criminelle, 16 février 1895, S. 1895, I, p.269

xlviii Loi $n^{\circ}$ 51-461 du 24 avril 1951 complétant la loi du 2 juillet 1850 relative aux mauvais traitements exercés envers les animaux domestiques

${ }^{\text {xlix }}$ Cour d'Appel de Toulouse, 1ère chambre, section 1, 3 avril 2000, JCP G 2000.II.10390, note P. Deumier

' Cour de Cassation, 2ème chambre civile, 10 juin 2004, nº2-17121

li Décision n²012-271 QPC du 21 septembre 2012

lii Código Penal de 1928 del General Primo de Rivera, artículo 810.4

liii Ley 8/1991, de 30 de abril, de protección de los animales

liv Ley 28/2010, de 3 de agosto, de modificación del artículo 6 del texto refundido de la Ley de protección de los animales, aprobado por el Decreto legislativo 2/2008

Iv Decreto Legislativo 2/2008, de 15 de abril, por el que se aprueba el Texto refundido de la Ley de protección de los animales 
Ivi Ley 8/1991, de 30 de abril, de protección de los animales

Ivii Ley 10/1990, de 27 de agosto, de protección y defensa de los animales de compañía

Iviii Ley $11 / 2003$, de 24 de noviembre, de protección de los animales

lix Loi $n^{\circ}$ 64-690 du 8 juillet 1964 modifiant la loi $n^{\circ} 63-1143$ du 19 novembre 1963 relative à la protection des animaux

${ }^{1 x}$ Jean-Jacques Rousseau, Discours sur l'origine et les fondements de l'inégalité parmi les hommes, Préface :

"Si je suis obligé de ne faire aucun mal à mon semblable, c'est moins parce qu'il est un être raisonnable que parce qu'il est un être sensible; qualité qui étant commune à la bête et à l'homme, doit au moins donner à l'un le droit de ne pas être maltraitée inutilement par l'autre." 